Letter to Editor

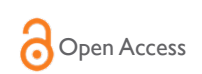

CrossMark

\title{
Invasions Changing Marine Biodiversity
}

Volume 5 Issue 2 - 2017

\section{Letter To Editor}

A recent and important perspective in ecology ${ }^{1}$ explains the loss of biodiversity in worldwide ecosystems while expressing the value of accurate data regarding both $\alpha$ and $\beta$ diversity. When using this approach to marine ecosystems we are confronted to a seriously understudied problem since marine community shifts are probably vast, complex and lacking an adequate research effort under a $\beta$ diversity perspective.

The biological shifts caused by Lessepsian migrants (LM) in the Mediterranean's eastern basin are certainly the most relevant species' turnover caused by man. As shown by AL Nunes et al. ${ }^{2}$ there are presently $435 \mathrm{LM}$ species, most of these already with viable populations in the Mediterranean's eastern basin and spreading westwards at a steady rhythm with a number already settling west of the Tunis Gulf.

The introduction of Lionfish in the Caribbean is also an example of serious threat to marine ecosystems. ${ }^{3}$

Worldwide marine biodiversity, as explained by Dornelas $\mathrm{M}$ et al. ${ }^{4}$ do not gain sufficient attention from many researchers and urgently need wide global actions that should already have been implemented. Although popular empirical feeling might well regard these type of marine invaders as just a different or novel food source - especially regarding fish species-for local fishermen communities, an aspect also referred by PalaC, ${ }^{3}$ facts do show that complex native communities being wiped out by alien species. This does not change $\alpha$ diversity since this may even increase with biological invasions albeit at the cost of extinctions amongst native and endemic species' guilds. ${ }^{5}$ This aspect does point that $\beta$ diversity is a variable that must surely be intensively monitored in marine realms.

As mentioned above, the dramatic species' shift caused by LM in the Mediterranean is evidence of the gigantic impact that invasive species do have in the oceans with the potential change of entire communities with no hope of recovery ${ }^{6}$ while the opposite trend indicates a full increase of alien species' populations with no signs of reversibility.

\section{Acknowledgments}

None.

\author{
Jo Barreiros \\ Centre for Ecology, Evolution and Environmental Changes/ \\ Azorean Biodiversity Group and Faculty of Agrarian and \\ Environmental Sciences, University of the Azores, Portugal \\ Correspondence: Centre for Ecology, Evolution and \\ Environmental Changes / Azorean Biodiversity Group and \\ Faculty of Agrarian and Environmental Sciences, University of \\ the Azores, Portugal, Email joao.ps.barreirors@uac.pt \\ Received: January 20, 2017 | Published: January 26, 2017
}

\section{Conflicts of interest}

None.

\section{References}

1. Pandolfi JM, Lovelock CE. Novelty trumps loss in global biodiversity. Science. 2014;344(6181):266-267.

2. Nunes AL, Katsanevakis S, Zenetos A, et al. Gateways to alien invasions in the European seas. Aquatic Invasions. 2014;9(2):133-144.

3. PalaC. As lionfish invade, divers defend threatened ecosystems.Science. 2014;343(6171):591.

4. Dornelas M, Gotelli NJ, McGill B, et al. Assemblage time series reveal biodiversity change but not systematic loss. Science. 2014;344:296-299.

5. Poloczanska ES, Brown CJ, Sydeman WJ, et al. Global imprint of climate change on marine life. Nature Climate Change. 2013;3:919-925.

6. Katsanevakis, Zenetos A, Belchior C, et al. Invading European Seas: Assessing pathways of introduction of marine aliens. Ocean \& Coastal Management. 2013;76:64-74. 